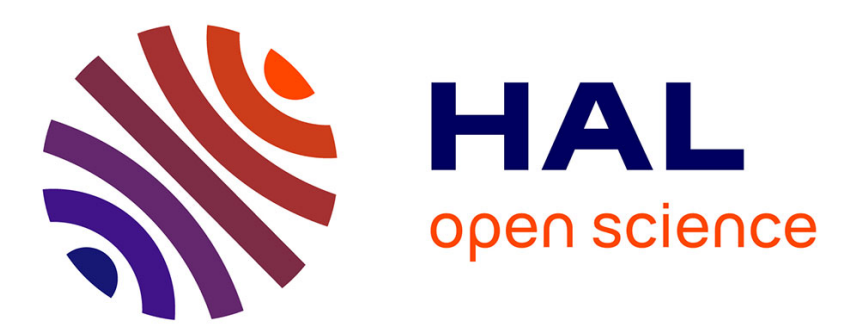

\title{
Improved determination of fundamental constants and test of fundamental physics with Doppler-free $\mathrm{THz}$ spectroscopy of $\mathrm{HD}+$
}

S. Alighanbari, G. Giri, Florin Lucian Constantin, V. Korobov, S. Schiller

\section{- To cite this version:}

S. Alighanbari, G. Giri, Florin Lucian Constantin, V. Korobov, S. Schiller. Improved determination of fundamental constants and test of fundamental physics with Doppler-free $\mathrm{THz}$ spectroscopy of $\mathrm{HD}+$. 2021 Conference on Lasers and Electro-Optics Europe \& European Quantum Electronics Conference, Jun 2021, Münich, Germany. hal-03335649

\author{
HAL Id: hal-03335649 \\ https://hal.science/hal-03335649
}

Submitted on 23 Sep 2021

HAL is a multi-disciplinary open access archive for the deposit and dissemination of scientific research documents, whether they are published or not. The documents may come from teaching and research institutions in France or abroad, or from public or private research centers.
L'archive ouverte pluridisciplinaire HAL, est destinée au dépôt et à la diffusion de documents scientifiques de niveau recherche, publiés ou non, émanant des établissements d'enseignement et de recherche français ou étrangers, des laboratoires publics ou privés. 


\title{
Improved Determination of Fundamental Constants and Test of Fundamental Physics with Doppler-Free THz Spectroscopy of $\mathrm{HD}^{+}$
}

\author{
S. Alighanbari ${ }^{1}$, G.S. Giri ${ }^{1}$, F.L. Constantin ${ }^{1,2}$, V. Korobov ${ }^{3}$, S. Schiller ${ }^{1}$ \\ 1. Institut für Experimentalphysik, Heinrich-Heine-Universität Düsseldorf, Düsseldorf, Germany \\ 2. Laboratoire PhLAM, CNRS UMR 8523, University of Lille, 59655 Villeneuve d'Ascq, France \\ 3. Bogoliubov Laboratory of Theoretical Physics, Joint Institute for Nuclear Research, Dubna, Russia
}

\begin{abstract}
Improved precision of Doppler-free rotational spectroscopy of trapped and laser-cooled $\mathrm{HD}^{+}$ions allows to confirm accurately high-precision ab-initio molecular ion quantum theory calculations and to determine fundamental constants more precisely than the CODATA2018 values.
\end{abstract}

The understanding of the quantum nature of atoms and molecules may be tested by comparing accurate theoretical ab-initio predictions with the results of precision spectroscopy experiments. A comparison based on the molecular hydrogen ions, the simplest three-body molecular systems, may be exploited also to determine the values of a set of fundamental constants and to search for any deviation of the nucleus-nucleus interaction from the Coulomb force. Achieving improvements in these results compared to the state-of-the-art is a challenging task on both experimental and theoretical sides.

The precision and resolution in rotational and vibrational spectroscopy of the molecular hydrogen ions, limited in the past by Doppler broadening and unresolved hyperfine structure of the spectral lines [1,2,3], has recently been improved using Doppler-free approaches [4,5]. On the theory side, the precision of the ab-initio predictions of the rovibrational energies has reached $10^{-11}$ or better [6], a level beyond the accuracy of the electron, proton and deuteron masses provided by the CODATA2018 adjustment [7].

We measured hyperfine components of the fundamental rotational transition of $\mathrm{HD}^{+}$at $1.3 \mathrm{THz}$ on sympathetically and rotationally cooled molecular ions in a linear radiofrequency trap [8]. An electronic $\mathrm{THz}$ source locked to a GPS-referenced hydrogen maser, an improved state-selective detection and a stable ion trap apparatus allowed reaching a fractional resolution of $3 \times 10^{-12}$ (Fig. 1(a)). After correction for the systematic frequency shifts induced by the Zeeman effect and the quadratic Stark effect due to the trapping electric field the experimental frequencies were determined with uncertainties as low as $17 \mathrm{~Hz}$. The theoretical frequency uncertainty is dominated by the spin energy errors, ranging from $0.2 \mathrm{kHz}$ to $1.4 \mathrm{kHz}$ [8].

The prediction of the spin structure theory at order $\alpha^{2}$ for a hyperfine splitting is confirmed within $4 \times 10^{-5}$ fractional theory uncertainty, while the fractional experimental uncertainty is 20 times smaller. Exploiting a composite frequency, defined as a suitable linear combination of hyperfine frequencies that cancel the spin theory uncertainty, confirms the quantum electrodynamics calculation at order $\alpha^{6}$ with a total fractional uncertainty of $4.8 \times 10^{-11}$ limited by the CODATA2018 uncertainties. This agreement allows to improve by 20 times the constraint on a hypothetical spin-independent fifth force between proton and deuteron with range $>1$ $\AA$. Assuming absence of such a force, our result determines the value of $R_{\infty} m_{e}\left(1 / m_{p}+1 / m_{d}\right)$ with an uncertainty 
2.4 times improved compared to CODATA2018 (Fig. 1(b)). Combining our result with Penning trap mass measurements in other groups, we deduce values for $\mathrm{m}_{\mathrm{e}} / \mathrm{m}_{\mathrm{p}}$ and $\mathrm{m}_{\mathrm{p}}$ with $2.0 \times 10^{-11}$ fractional uncertainties, 3 times smaller than and comparable with the CODATA2018 values, respectively.

\section{References}

[1] J.C.J. Koelemeij, et al, "Vibrational spectroscopy of $\mathrm{HD}^{+}$with 2-ppb accuracy," Phys. Rev. Lett. 98, 173002 (2007).

[2] U. Bressel, et al, "Manipulation of individual hyperfine states in cold trapped molecular ions and application to $\mathrm{HD}^{+}$ frequency metrology, " Phys. Rev. Lett. 108, 183003 (2012).

[3] J. Biesheuvel, et al, "Probing QED and fundamental constants through laser spectroscopy of vibrational transitions in $\mathrm{HD}^{+}$," Nat. Commun. 7, 10385 (2016).

[4] S. Alighanbari, et al, "Rotational spectroscopy of cold and trapped molecular ions in the Lamb-Dicke regime," Nat. Phys. 14, 555-559 (2018).

[5] S. Patra, et al, "Proton-electron mass ratio from laser spectroscopy of $\mathrm{HD}^{+}$at the part-per-trillion level," Science 369, 1238-1241 (2020).

[6] V.I. Korobov, et al, "Fundamental transitions and ionization energies of the hydrogen molecular ions with few ppt uncertainty," Phys. Rev. Lett. 118, 233001 (2017).

[7] E. Tiesinga, et al, "Values of fundamental physical constants. NIST https://physics.nist.gov/cuu/Constants/index.html," (2019).

[8] S. Alighanbari, et al, "Precise test of quantum electrodynamics and determination of fundamental constants with $\mathrm{HD}^{+}$ ions," Nature 581, 152-158 (2020).

\section{Figure caption}
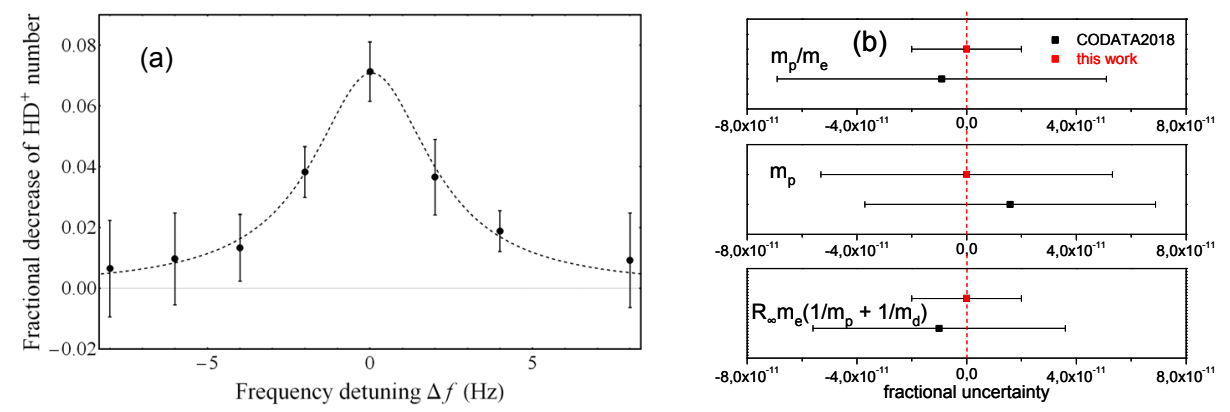

Fig. 1 (a) Rotational spectroscopy of the transition $\left(v, N, \mathrm{G}_{1}, \mathrm{G}_{2}, \mathrm{~F}, \mathrm{~m}_{\mathrm{F}}\right)=(0,0,1,2,2,2) \rightarrow(0,1,1,2,3,3)$ of $\mathrm{HD}^{+}$.

(b) Determination of fundamental constants from theory-experiment comparison. 